\title{
EVALUATION OF THYROID FUNCTION TESTS BEFORE AND AFTER SYSTEMIC ISOTRETINOIN TREATMENT OF ACNE VULGARIS PATIENTS
}

\author{
By
Fayrouz Adel Ahmed, Amr Mohamed Zaky and Sameh Mohamed Abd El-Qodos* \\ Department of Dermatology, Venereology and Andrology, Faculty of Medicine, Al-Azhar \\ University \\ Corresponding author: Fayrouz Adel Ahmed, \\ E-mail: fayrouz_ade196@gmail.com
}

\begin{abstract}
Background: Acne, also known as acne vulgaris, is a long-term skin disease that occurs when hair follicles are clogged with dead skin cells and oil from the skin. It is characterized by blackheads or whiteheads, pimples, oily skin, and possible scarring.

Objective: To evaluate TSH, free T3 and free T4 in patients with acne treated with systemic isotretinoin at baseline and after three months of treatment to find any alteration in TFTs.

Patients and methods: This study was conducted on thirty patients with treatment for acne vulgaris. The study was done in Al-Azhar university hospitals from June 2018-February 2019.

Results: The mean and standard deviation of age was $30.62 \pm(7.6)$ years. There was no statistical difference in age distribution, i.e. normally distributed. As regard sex, there was 38 (76\%) females and $12(24 \%)$ males. The ratio of female to male was 3:1.Serum levels of thyroid function tests were compared by using Wilcoxon comparison test for non-parametric tests. There was a statistically significant difference between both variables. TSH levels markedly elevated in comparison to before treatment. In contrast to TSH levels, T3 and T4 reduced significantly when compared to before treatment levels.

Conclusion: Dermatologists need to be aware about possible TFTs abnormalities during systemic isotretinoin therapy. Clinical symptoms regarding thyroid disease for both hypothyroidism and hyperthyroidism should be evaluated regularly at visits, and patients with concomitant thyroid function disease should be monitored for TFTs.
\end{abstract}

Keywords: Thyroid function, Systemic Isotretinoin Treatment, Acne vulgaris.

\section{INTRODUCTION}

Acne primarily affects skin with greater number of oil glands, including the face, upper part of chest, and backduring puberty in both sexes, acne is often brought on by an increase in androgens such as testosterone. Excessive growth of the bacteria propionibacterium acnes, which is normally present on the skin, is often involved (Poli and Revuz, 2018).

Isotretinoin (13-cis retinoic acid), a biologically active metabolite of vitamin $A$, has been used in the treatment of moderate or severe nodulocystic acne, disorders of sebaceous gland and keratinization and in the prevention of 
skin cancer (Al-Kathiri and Al-Najjar, 2018).

With the increasing use of isotretinoin especially for the treatment of acne vulgaris and other disorders, the interest in the effect of this retinoid on other organs and the metabolic system has increased considerably (Gualtieri et al., 2020).

The effect of vitamin $A$ on the synthesis of thyroid hormone has been known for many years. Simkins demonstrated successful treatment of patients with hyperthyroidism with a massive dose of vitamin A (Khiali et al., 2018).

The aim of this study was to evaluate $\mathrm{TSH}$, free T3 and free T4 in patients with acne treated with systemic isotretinoin at baseline and after three months of treatment to find any alteration in TFTs.

\section{PATIENTS AND METHODS}

This study was conducted on fifty patients with acne vulgaris. The study was done atn Al-Azhar University Hospitals from June 2018-February 2019.

This was a prospective, uncontrolled and observational study for 50 patients. IRB approval was taken prior to launch the study.

\section{Inclusion criteria:}

All patients with acne vulgaris treated with systemic isotretinoin for at least 3 months.

\section{Exclusion criteria:}

1. All patients experienced clinical symptoms of hypothyroidism such as increased sensitivity to cold, unexplained weight gain, puffy face, hoarseness, thinning hair, slowed heart rate or impaired memory after isotretinoin therapy for 4 months.

2. Patients with hyperthyroidism.

3. Patients with liver affection.

4. Patients with systemic disease affecting thyroid function.

5. Any contraindication of systemic isotretinoin treatment (pregnancy, lactating, age.....etc).

\section{All patients were exposed to:}

- History taking.

- Clinical and physical examination.

- Informed written consent from the patient.

Acne type and severity and grading were assessed into:

I. Mild: Few to numerous comedones, few to several papules or pustules and no nodules.

II. Moderate: Numerous or extensive comedones, several-to-many papules or pustules and few to several nodules.

III. Severe: Numerous or extensive papules or pustules and many nodules.

Isotretinoin therapy was initiated at a dose of $0.5-0.8 \mathrm{mg} / \mathrm{kg}$ body weight. The drug was administered to acne patients twice daily with meals. Treatment was continued for at least 3 months.

Biochemical parameters were screened prior to initiation (pre-treatment) and 3 months after the start of isotretinoin treatment, (post-treatment). Those parameters were free triiodothyronine, free thyroxine, thyroid stimulating 
hormone, anti-thyroid peroxidase and antithyroglobulin.

Fasting blood samples were obtained by venepuncture of the large antecubital veins after a12-h fasting period. The samples were centrifuged immediately, the plasma separated and all samples were studied using the same kits. Free triiodothyronine, free thyroxine and thyroid stimulating hormone, were measured using electrochemiluminescent immunoassay methods.

\section{Statistical Analysis:}

Analysis of data was done by IBM computer using SPSS (statistical program for the social science version 25) as follows: Description of quantitative variables as mean, SD and range. Description of qualitative variables as number and percentage median, interquartile range. Mann Whitney test was used instead of unpaired t-test in nonparametric data. Wilsxon test was used to compare quantitative variables in the same group before and after.

\section{RESULTS}

The mean and standard deviation of age was 30.62(7.6) years. There was no statistical difference in age distribution (i.e. normally distributed) (Figure 1). As regard sex, there was $38(76 \%)$ female and $12(24 \%)$ male. The ratio of female to male was 3:1 (Figure 2).

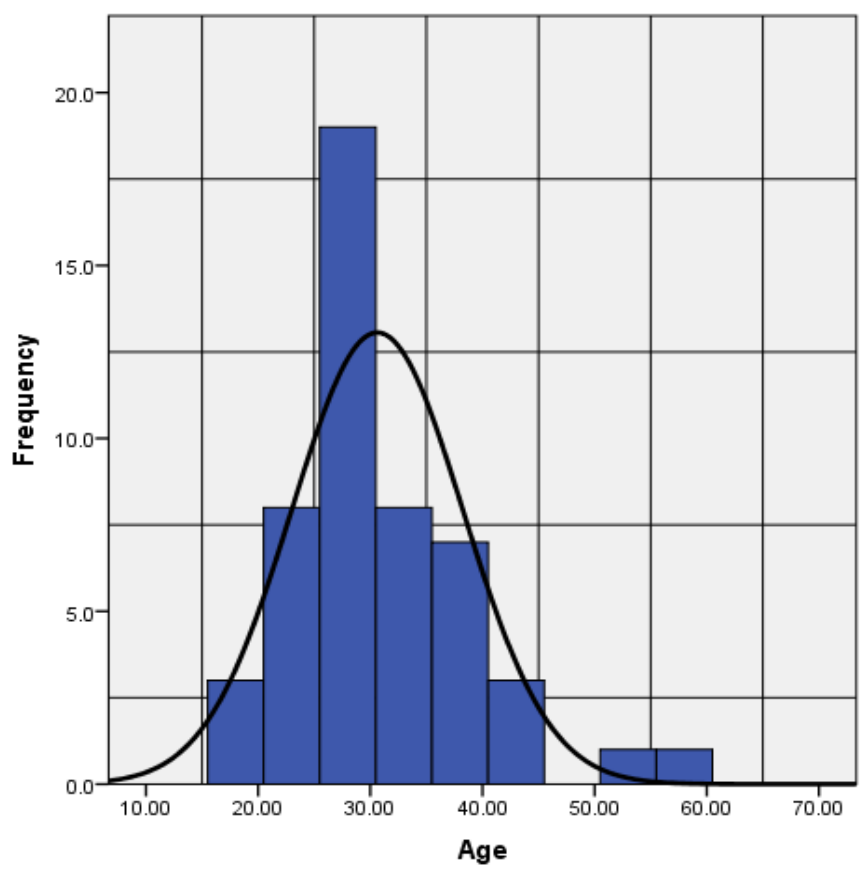

Figure (1): Age histogram 


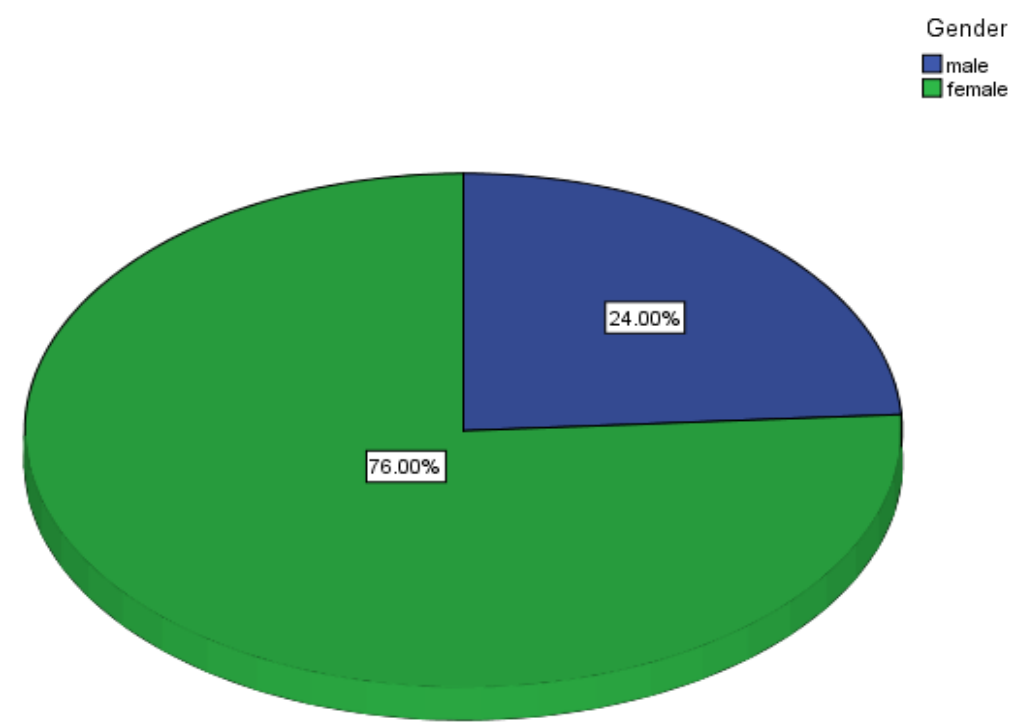

Figure (2): Pie chart of gender.

Prior to induction of therapy, thyroid function tests were drawn and tabulated in Table 1. Figures 3-5 illustrated the distribution of data in histogramic distribution, in all figures; normal range was plotted to facilitate understanding of distribution.

Table (1): Statistical description of thyroid function tests prior and after induction of treatment

\begin{tabular}{|c|c|c|c|c|}
\hline \multicolumn{2}{|c|}{ Pre Induction of Treatment } & TSH & T3 & T4 \\
\hline \multicolumn{2}{|c|}{ Mean } & 1.9354 & 3.2386 & 13.9886 \\
\hline \multirow{2}{*}{$\begin{array}{l}95 \% \text { Confidence } \\
\text { Interval for Mean }\end{array}$} & Lower Bound & 2.6805 & 13.1884 & 13.1884 \\
\hline & Upper Bound & 3.7967 & 14.7888 & 14.7888 \\
\hline \multicolumn{2}{|c|}{$5 \%$ Trimmed Mean } & 1.8661 & 2.9958 & 14.0783 \\
\hline \multicolumn{2}{|c|}{ Median } & 1.8050 & 2.8450 & 13.7350 \\
\hline \multicolumn{2}{|c|}{ Variance } & 1.010 & 3.856 & 7.928 \\
\hline \multicolumn{2}{|c|}{ Std. Deviation } & 1.00491 & 1.96367 & 2.81576 \\
\hline \multicolumn{2}{|c|}{ Minimum } & .43 & .46 & 2.41 \\
\hline \multicolumn{2}{|c|}{ Maximum } & 4.80 & 15.82 & 19.08 \\
\hline \multicolumn{2}{|c|}{ Range } & 4.37 & 15.36 & 16.67 \\
\hline \multicolumn{2}{|c|}{ Interquartile Range } & .85 & .66 & 2.70 \\
\hline \multicolumn{2}{|c|}{ Post induction of treatment } & $\mathrm{TSH}$ & T3 & $\mathrm{T} 4$ \\
\hline \multicolumn{2}{|c|}{ Mean } & 3.1190 & 3.0830 & 12.9122 \\
\hline \multirow{2}{*}{$\begin{array}{l}\text { 95\% Confidence } \\
\text { Interval for Mean }\end{array}$} & Lower Bound & 2.74 & 2.646 & 12.1378 \\
\hline & Upper Bound & 3.49 & 3.51 & 13.6866 \\
\hline \multicolumn{2}{|c|}{$5 \%$ Trimmed Mean } & 3.0222 & 2.8529 & 12.8736 \\
\hline \multicolumn{2}{|c|}{ Median } & 2.7800 & 2.8100 & 12.3700 \\
\hline \multicolumn{2}{|c|}{ Variance } & 1.728 & 2.354 & 7.426 \\
\hline \multicolumn{2}{|c|}{ Std. Deviation } & 1.31466 & 1.53441 & 2.72504 \\
\hline \multicolumn{2}{|c|}{ Minimum } & 1.07 & 1.70 & 2.60 \\
\hline \multicolumn{2}{|c|}{ Maximum } & 7.09 & 12.39 & 20.80 \\
\hline \multicolumn{2}{|c|}{ Range } & 6.02 & 10.69 & 18.20 \\
\hline \multicolumn{2}{|c|}{ Interquartile Range } & 1.91 & .66 & 2.44 \\
\hline
\end{tabular}


Serum levels of thyroid function tests were compared by using Wilcoxon comparison test for non-parametric tests. It has been found that there was a statistically significant difference between both variables Again, TSH levels were markedly elevated in comparison to before treatment $(0.00001)$. In contrast to TSH levels, T3 and T4 were reduced significantly when compared to before treatment levels (Table 2).

Table (2): Mean comparison between after and before treatment thyroid serum concentration

\begin{tabular}{|c|c|c|c|c|c|c|}
\hline $\begin{array}{l}\text { Serum } \\
\text { concentration }\end{array}$ & $\begin{array}{c}\text { Pre- } \\
\text { treatment }\end{array}$ & $\begin{array}{c}\text { Post- } \\
\text { treatment }\end{array}$ & Z score & $\begin{array}{c}\text { 95\% } \\
\text { CI }\end{array}$ & P value & Sig. \\
\hline TSH & $1.9354 \pm 1$ & $3.11 \pm 1.3$ & -6.154 & $0.71-1.63$ & 0.00001 & HS \\
\hline T3 & $3.2386 \pm 1.9$ & $3.08 \pm 1.5$ & -3.007 & $2.7281-3.1259$ & 0.003 & $\mathrm{~S}$ \\
\hline T4 & $13.9886 \pm 2.8$ & $12.9122 \pm 2.7$ & -4.861 & $12.9-14.27$ & 0.000001 & $\mathrm{HS}$ \\
\hline
\end{tabular}

\section{DISCUSSION}

This study was conducted on thirty patients with treatment for acne vulgaris. The study was done in Al-Azhar University Hospitals from June 2018February 2019. The study aimed to evaluate $\mathrm{TSH}$, free $\mathrm{T} 3$ and free $\mathrm{T} 4$ in patients with acne treated with systemic isotretinoin at baseline and after three months of treatment to find any alteration in TFTs.

In our study the mean and standard deviation of age was $30.62 \pm 7.6$ years. There were $76 \%$ females and $24 \%$ males. The ratio of female to male was $3: 1$. In Ylldırim et al. (2016) the mean $20.47 \pm$ 3.15 years.

Nugroho and Schweiger, (2017) recorded a case of 16 years girl with hyperthyroidism and a known history of retinoid treatment for acne vulgaris.

Isotretinoin is the sole systemic retinoid that is efficiently used in the treatment of severe acne. However, its potential side effect on thyroid functions remains unknown although many studies have focused on it before (Masood and Hakeem, 2011).

In our study, serum levels of thyroid function tests were compared by using Wilcoxon comparison test for nonparametric tests. It has been found that there was a statistically significant difference between both variables. Again, TSH levels were markedly elevated in comparison to before treatment. In contrast to TSH levels, T3 and T4 reduced significantly when compared to before treatment levels.

The earliest study regarding retinoid's effects on sTFTs showed that a dosage of $0.8 \mathrm{mg} / \mathrm{kg} /$ day oral isotretinoin for three months led to decrease in serum T4 levels where normal levels were restored one month after cessation of treatment (Ylldirtm et al., 2016) reported a case of acute thyrotoxicosis in a 26-year-old male returned to normal ranges 12 weeks after cessation of isotretinoin treatment (Masood and Hakeem, 2011).

Although bexarotene, a RXR selective retinoid, is clearly known to lead hypothyroidism both by central way and 
by changing peripheral metabolism of thyroid hormones (Smit et al., 2010), Possible mechanism for isotretinoin's effects on STFTs are yet to be determined.

In 2015, a study from Turkey revealed that serum fT3 and TSH levels decreased significantly after three months of isotretinoin treatment (Karadag et al., 2015).

Decreases in serum TSH and fT3 levels may be induced by central hypothyroidism due to RXR-mediated suppression of TSH $\beta$ gene expression (Karadag et al., 2015). Isotretinoin's effect on thyroid metabolism may be dose-dependent due to the fact that continuous high and low dose isotretinoin treatment decreased serum fT3 levels, while no effect was reported with intermittent treatment (Karadag et al., 2015).

Whether the values of sTFTs can revert back after the end of the isotretinoin treatment remains to be determined. Short and long-term effects of different dosages of isotretinoin treatment on serum thyroid hormones needs further evaluation.

\section{CONCLUSION}

Dermatologists need to be aware about possible TFTs abnormalities during systemic isotretinoin therapy. Clinical symptoms regarding thyroid disease for both hypothyroidism and hyperthyroidism should be evaluated regularly at visits, and patients with concomitant thyroid function disease should be monitored for TFTs.

\section{REFERENCES}

1. Al-Kathiri L and Al-Najjar T (2018): Severe Nodulocystic Acne not responding to Isotretinoin Therapy Successfully Treated with
Oral Dapsone. Oman Medical Journal, 33(5): 433-436.

2. Gualtieri B, Panduri S, Chiricozzi A and Romanelli M (2020): Isotretinoin-triggered acne fulminans: a rare, disabling occurrence. $\mathrm{G}$ Ital Dermatol Venereol., 155(3):361-362.

3. Karadag AS, Takci Z, Ertugrul D, Bilgili SG, Balahoroglu R and Takir M (2015): The Effect of Different Doses of Isotretinoin on Pituitary Hormones'. Dermatology, 230(4): 354-359.

4. Khiali S, Gharekhani $A$ and EntezariMaleki T (2018): Isotretinoin; A review on the Utilization Pattern in Pregnancy. Advanced Pharmaceutical Bulletin Iran, 8(3): 377-382.

5. Masood MQ and Hakeem H. (2011): Isotretinoin Associated Reversible Hypothyroidism. Thyroid, 21(9): 1039-1040.

6. Nugroho $J$ and Schweiger B. (2017): Isotretinoin as a Possible Environmental Trigger to Autoimmunity in Genetically Susceptible Patients. Case Reports in Pediatrics, 2017: 1-3.

7. Pile HD and Nicolas D. (2018): Isotretinoin. Treasure Island. FL. Europe PMC, 2018: 1-8.

8. Poli F and Revuz J. (2018): Acne flare on isotretinoin: A pointer to diagnosis of hidradenitis suppurativa. Annales de Dermatologie et de Venereologie, 146(1):4-8.

9. Smit JWA, Stokkel MPM, Pereira AM, Romijn JA and Visser TJ. (2010): Bexarotene-induced hypothyroidism: bexarotene stimulates the peripheral metabolism of thyroid hormones. Journal of Clinical Endocrinology and Metabolism, 92: 2496-2499.

10. Yıldırım N, Doğan S and Atakan N (2016): Evaluation of thyroid function tests of acne vulgaris patients treated with systemic isotretinoin. Journal of Dermatological Treatment, 28: 141-144. 


\section{تقيبيم إختبارات وظائف الغلة اللدرقية قبل و بعد العلاج بالايزوتريتنوين في مرضى العلّ الشائع}

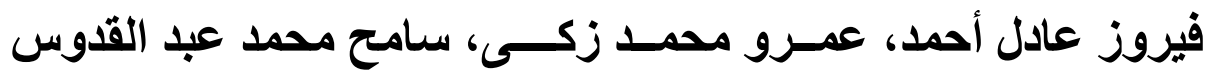
قسم الأمراض الجلاية والتناسلية وأمراض الذكورة، كلية الطب، جامعةلأزهر

E-mail: fayrouz_ade196@gmail.com

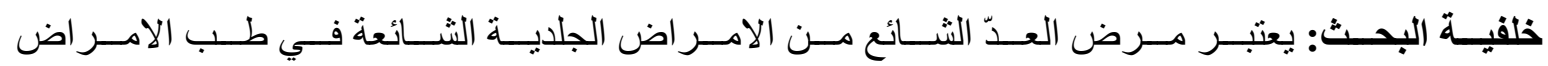

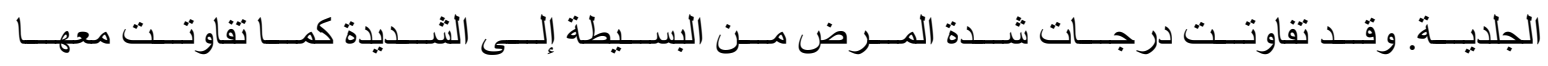

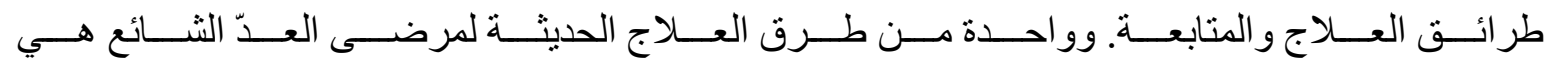

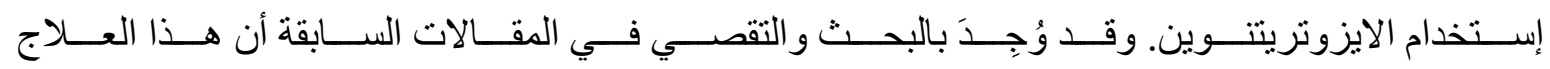

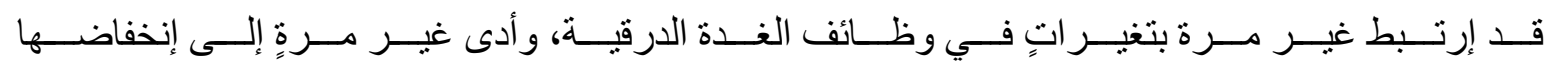
و التسبب بمتلازمة نقص إفراز الغدة الدرقية.

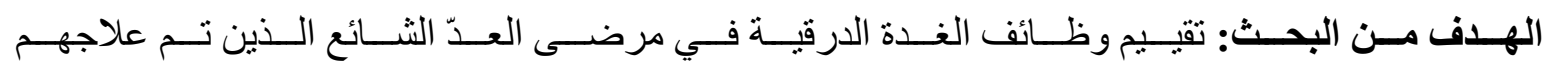

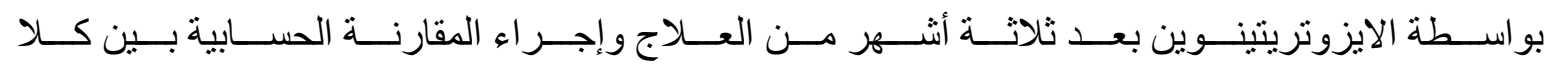
القيميتين لكل وظيفة.

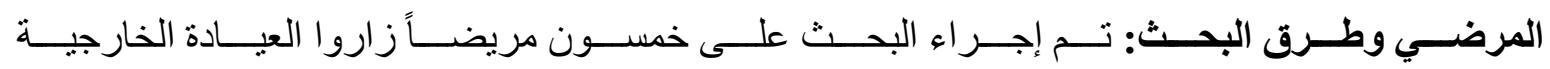

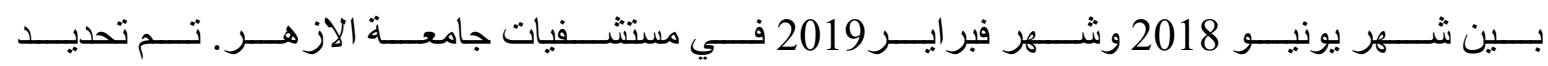

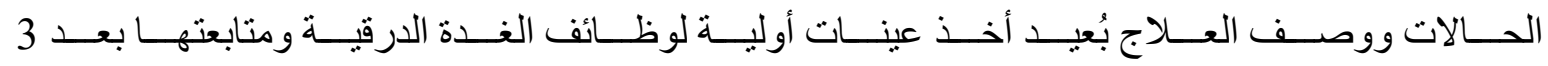
أثنر.

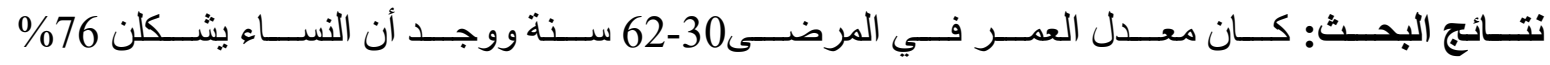

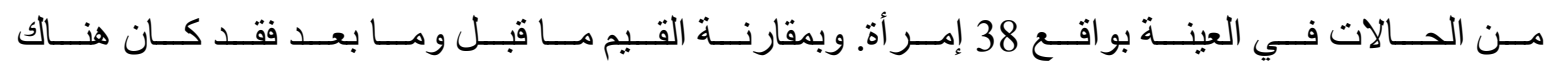

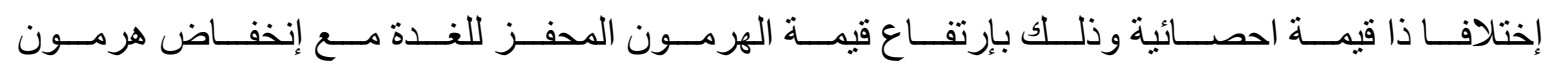
الغذة الثلاثي والرباعي بما يثبر لضعف قابلية الغدة نفسها على الافراز.

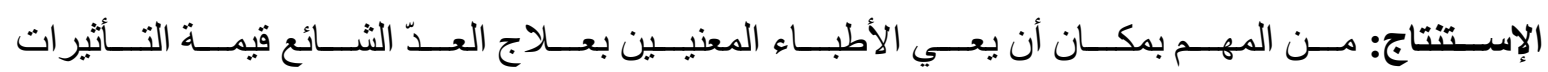

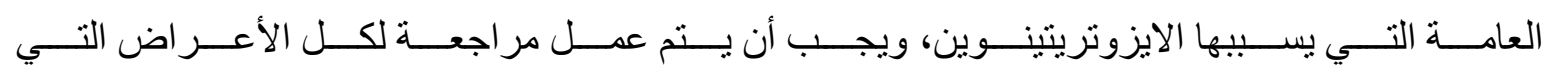
تر افق المريض بعد العلاج وفي كل زيارة. الكلمات الدالة : وظائف الغدة الدرقية - الايزوتريتنموين - العد الثائع 